EGU2020-20723, updated on 26 Jun 2020

https://doi.org/10.5194/egusphere-egu2020-20723

EGU General Assembly 2020

(c) Author(s) 2020. This work is distributed under

the Creative Commons Attribution 4.0 License.

\title{
Utilization of abandoned hydrocarbon reservoirs for deep geothermal heat storage
}

\author{
Kai Stricker ${ }^{1}$, Jens Grimmer ${ }^{1}$, Joerg Meixner ${ }^{2}$, Ali Dashti ${ }^{1}$, Robert Egert ${ }^{1}$, Maziar Gholamikorzani ${ }^{1}$, \\ Katharina Schaetzler ${ }^{1}$, Eva Schill ${ }^{1}$, and Thomas Kohl ${ }^{1}$ \\ ${ }^{1}$ Karlsruhe Institute of Technology, Institute of Applied Geosciences, Division of Geothermal Research, Germany \\ (kai.stricker@kit.edu) \\ ${ }^{2}$ Regierungspräsidium Freiburg - Landesamt für Geologie, Rohstoffe und Bergbau
}

Energy transition involves an increasing demand for renewable energies. Room heating and hot water account for the majority of the energy demand of private households. Thus, seasonal storage of excess heat produced during the summertime and extracted during the wintertime is of paramount importance. High temperature heat storage in the subsurface may be realized in abandoned hydrocarbon reservoirs worldwide as these reservoirs have already been extensively characterized concerning their geology, geo- and petrophysical properties as well as their depths and geometries. Although these hydrocarbon reservoirs are relatively well characterized, their potential use for geothermal heat storage has not yet been investigated. Here we focus in a first approach on abandoned oilfields of the Upper Rhine Graben (URG) in SW Germany with the aim to assess their potentials for geothermal heat storage. While geothermal production commonly targets fractured reservoirs to obtain economically viable flowrates, geothermal heat storage will aim at reservoirs with high porosities. As the productivity of hydrocarbon reservoirs is commonly controlled by their porosities, they appear as viable targets for high temperature heat storage.

We have characterized 20 abandoned hydrocarbon reservoirs in the URG, which were productive for more than five years, in Cenozoic sandstones in depths of approximately $200-1800 \mathrm{~m}$. Our characterization is based on published data of their production histories, reservoir geology, and petrophysical properties. Most reservoirs in the URG are stacked reservoirs with inflow of hydrocarbons into the borehole from multiple stratigraphic units, as for example in Landau and Leopoldshafen, biasing an assignment of respective reservoir productivity. For heat storage injection pressure needs to be well controlled to avoid undesired hydraulic fracturing. Therefore, (theoretically) infinite reservoirs with high transmissivities appear to be more attractive and less risky than confined reservoirs.

The production histories of the various hydrocarbon reservoirs show typical patterns with a rapid increase of the annual production, followed by a slower decrease of production (tailing) before hydrocarbon production was shut down. Most reservoirs in Cenozoic sandstones show porosities of 10 to $20 \%$ with some extreme values of up to $30 \%$. Associated permeabilities vary from 0.1 to $100 \mathrm{mD}$ with some extreme values of up to $1000 \mathrm{mD}$. Data show a non-linear relationship between porosity and permeability. During hydrocarbon production water-oil ratios increase until 
unalluring water-oil were produced. We evaluate the potential of abandoned hydrocarbon reservoirs in the URG for heat storage by developing generic numerical models to constrain limiting conditions. The uncertainties of input parameters and their impact on heat storage potential will be addressed by a sensitivity analysis. Potential reservoirs for heat storage may be defined based on energy recovered over invested energy (EROI). Preliminary results of our numerical models show a strong dependency of the storage potential on increasing flowrates as well as on decreasing thermal conductivities of the reservoir and especially the confining layers below and above. 